\title{
REVIEW
}

\section{The endocrine role between $\beta$ cells and intra-islet endothelial cells}

\author{
Zilong Cao and Xiaoyu Wang \\ School of Medicine, Shandong University, Shandong 250012, P.R.China
}

\begin{abstract}
The islets of Langerhans is the endocrine function region of pancreas, which exist in five cell types. The majority of endocrine cells are insulin-secreting $\beta$ cells, mixed up with glucagon-secreting $\alpha$-cells. The islets of Langerhans are highly vascularized, and the capillary network around the islet is about five times denser than that in the exocrine tissues. It guarantees endocrine cells adequately contact with the capillary networks. Above mentioned is the basis of deep study the interaction between $\beta$ cells and capillary. Increasing number of studies contribute to the consensus that endothelial cells have positive effects in the islet microenvironment. Endothelial cells can act as endocrine cells which release many active substances, such as hepatocyte growth factors (HGF), thrombospondin-1(TSP-1), laminins, and collagens by means of different molecule pathways, inducing $\beta$ cells differentiation, proliferation, survivor, and insulin release next to the vessels. Apart from the effect of endothelial cells on $\beta$ cells by paracrine fashion, the islets can utilize VEGF-A, angiopoietin-1 and insulin signaling to increase the interaction with endothelial cells. As the endocrine role of endothelial cells to $\beta$ cells, it may be a novel target to stimulate $\beta$ cells regeneration, promote vascularization post islet transplantation strategy in the treatment of diabetes mellitus.
\end{abstract}

Key words: $\beta$ cells, Endothelial cells, Endocrine, Insulin

THE HUMAN pancreas plays a key role in the digestive and endocrine system. It is a glandular organ functioning as an endocrine gland, which produces many hormones involved in maintaining metabolic homeostasis. These include insulin, glucagon, pancreatic polypeptide, somatostatin (SS), ghrelin [1], and an organ in the digestive system that secretes digestive enzymes containing pancreatic juice, which is responsible for the absorption and digestion of nutrients within the small intestine.

The pancreas can function as an endocrine and exocrine gland. The endocrine function region of the pancreas consists of approximately a million clusters of cells, known as the islets of Langerhans [2]. The islets of Langerhans essentially exist in five cell types, and are classified by their secretion [1]. Specifically, the majority of endocrine cells are insulin-secreting $\beta$ cells, mixed up with glucagon-secreting $\alpha$-cells

Submitted Feb. 2, 2014; Accepted Mar. 2, 2014 as EJ14-0045

Released online in J-STAGE as advance publication Mar.29, 2014

Correspondence to: Zilong Cao, Room 1004, Building 7, No.115

Wenhua Xi Road, Jinan, Shandong, 250012 P.R. China

E-mail: xiaocaoshangfei@126.com and somatostatin-secreting $\delta$-cells [1]. The islets of Langerhans are highly vascularized, and the capillary network around the islet is about five times denser than that in the exocrine tissues. It guarantees endocrine cells adequately contact with the capillary networks [3] which is the basis of deep study the interaction between $\beta$ cells and capillary. Additionally, the capillary wall is composed of one-layer vascular endothelial cells, which show a high permeability, and consist of ten times more fenestrae than those endothelial cells present in the exocrine pancreas [4]. It guarantees a higher capacity in the exchange of oxygen, carbon dioxide, nutrients, and chemical waste substances between the blood and the surrounding tissues [4]. Overall, the hormone secreted by the islets is easily distributed to the whole body, playing a main function in the homeostasis of blood glucose concentration and glucose metabolism.

As we know, type 1 diabetes is due to autoimmune destruction of $\beta$ cell, which results in lacking of insulin, leading to hyperglycemia [5]. Insulin therapy is the current common method, while the living quality of patients is reduced. Therefore it is crucial to increase the regeneration of self islet $\beta$ cell and 
production of insulin.

Lots of evidences prove the islet endothelial cells having significant relationship with the function of islets. When suffers hyperglycemia and glucose toxicity, islet endothelial cells are vulnerable to destruction [6]. In the early phase of type 1 diabetes, endothelial cells can attract immune cells by leukocyte-homing receptors to induce $\beta$ cell destruction [7]. Islet transplantation is an experimental treatment for type 1 diabetes; it uses isolated donor islets into another person. Studies found isolated rat islets can prolong the islet graft survival in diabetic rats by co-transplantation with endothelial cells [8]. In early processes of islet transplantation, when the donor islet is transplanted, donor islet endothelial cells will participate in neovascularization, increasing the survival of $\beta$ cells [9]. After $\beta$ cells injury, endothelial cells promote pancreatic stem cell proliferation and islet regeneration [10]. Endothelial cells can enhance embryonic stem cell differentiate into pancreatic progenitors and $\beta$ cells in vitro through bone morphogenetic protein (BMP) pathway, which controls pancreatic cell proliferation and differentiation [11].

Overall, it's definitely that endothelial cells can affect the function of islets. Neovascularization is a very important effect, while recent many studies focus on its endocrine roles to islets.

\section{The endocrine role of islet endothelial cells to $\beta$ cells}

Besides acting as a barrier, endothelial cell also has endocrine property, and it is attached importance to continuous growth, differentiation, and function of $\beta$ cell. It can release many vasoactive substances and growth factors, which affect the function of $\beta$ cell in a paracrine fashion, leading to the production and secretion of insulin $[4,12]$.

\section{Hepatocyte growth factor}

Hepatocyte growth factor (HGF) is a cytokine which promotes cell proliferation, motility, and morphogenesis [13]. It can bind to the tyrosine kinase membrane receptor c-Met [14, 15], which activates RAS and phosphatidylinositol (PI) 3-kinase (PI3K) pathway, mediates proliferation and survival signals $[16,17]$. Studies found that HGF has strong positive effects on $\beta$ cells mitogenesis, differentiation, glucose sensing, and transplant survival [18]. In early development,
HGF and c-Met are highly expressed in the pancreas, and maintained at a low level in adults, which seems HGF and c-met pancreatic gene expression are age dependent [19]. HGF can be released by endothelial cells [4], and bind to c-Met receptor on $\beta$ cells [20]. It activates phosphatidylinositol (PI) 3-kinase (PI3K) pathway, generates phosphorylated phosphoinositides binding to pro-survival intracellular signaling molecule protein kinase $\mathrm{B}(\mathrm{PKB} / \mathrm{Akt})$, enhancing $\beta$ cells proliferation and survival [21]. PKC zeta is a novel downstream target of PI3K-phosphoinositide-dependent kinase-1 (PDK-1) activation, which is found essential for HGF induced $\beta$ cell proliferation [22]. In rat insulin II promoter (RIP)-HGF transgenic mice, HGF are overexpressed in $\beta$ cells, leading to a 2 -fold increase in insulin; $\beta$ cells replication rates and islet mass are two to three times higher than control. Moreover, the islet number per pancreatic area is increased by approximately 50\% [23], which shows resultant mitogenesis, pro-differentiation, and anti-apoptotic properties [18]. In streptozotocin (STZ)-induced diabetic mice, when islets are transplanted, HGF is essential for the amelioration of hyperglycemia [24]. It's interesting that during pregnancy in adult rats, the production of HGF is increased, concluded by overexpression of prolactin [25]. Overall, these studies suggest that HGF is a important factor to islets, so HGF gene therapy is a novel way to improve successful islet transplantation and treat diabetes [26].

\section{Thrombospodin-1}

Thrombospodin-1 (TSP-1) is a matricellular glycoprotein that interacts with growth factors, cytokines, other matrix components and membrane proteins, regulating cell proliferation, migration and apoptosis [27]. It is important to the activation of transforming growth factor $\beta-1$ (TGF $\beta-1)$ in vivo, which induce cell growth, differentiation, and immune modulation [28]. In normal islets, TSP-1 is primarily produced by endothelial cells [29], and it can induce the islets produce TGF- $\beta$ [21], which may initiate a signaling cascade leading to Rho-like GTPases and stress-activated protein kinase/c-Jun N-terminal kinase (SAPK/ JNK) pathway activation [30], to establish and maintain defining features of mature pancreatic $\beta$ cells [31]. Studies found that in TSP-1-deficient mice, glucose-stimulated insulin release is decreased [29], which therefore suggests the critical role of TSP-1 
in insulin production. In high glucose model, both overexpression of PKC and TGF- $\beta 1$ regulate TSP-1 expression, and that glucose-induced increase of TSP- 1 can synergistically facilitate TGF- $\beta 1[32]$. On the other hand, TSP-1 plays roles in antiangiogenesis [33]. It can inhibit endothelial tubule formation in vitro [34], and express antiangiogenic activities in vivo [34]. It interacts with the endothelial cell surface receptors CD36 [35], activates Src family kinases Fyn/Yes, and increases expression of death receptors and Fas ligand, leading to cell apoptosis [34]. So it can induce the destruction of islet capillary network in islets, showing the negative aspects to $\beta$ cell.

\section{Basement membrane}

Basement membranes (BMs) are extracellular matrix that lie along the basal surface of endothelial cells, which look like a sleeve around the endothelium, supporting the architecture of vessel [36]. They are primarily composed of collagen, laminin, fibronectin, and heparan sulfate [36]. In islets, as $\beta$ cells cannot form a basement membrane [37], BMs are primarily formed by endothelial cells [36]. Vascular basement membrane directly contact with the pancreatic islet cells [38], so they play an important role of the physiological microenvironment to pancreatic islet cells [38, 39]. Many evidences found that disruption relationship between islet cells and basement membrane, or the loss of basement membrane, both leading to the apoptosis of islets cells [40].

Collagen-I and IV are primarily collagen in basement membrane [39; 41], and $\alpha 1 \beta 1$-integrin and $\alpha 3 \beta 1$-integrin are the primary collagen receptors in both fetal and adult $\beta$ cells $[42 ; 43]$. In vitro, cultured $\beta$ cells can adhere to and migrate on collagen [43]. When collagen bind to $\alpha 1 \beta 1$-integrin, it can activate focal adhesion kinase and extracellular signal-regulated kinases phosphorylation (FAK-ERK) pathway, increasing pancreatic and duodenal homeobox $1(\mathrm{Pdx}-1)$ expression, which is a transcription factor necessary for pancreatic development and $\beta$ cell maturation, and protect from caspase 3 cleavage, which is activated in the apoptotic cell $[42 ; 44]$. It regulates glucose metabolism, contributes to the survival and function of $\beta$ cell in vivo [44]. When binding to $\alpha 3 \beta 1$-integrin, it can activate phosphatidylinositol (PI) 3-kinase (PI3K), which increase the lipid phosphatidylinositol $(3,4,5) \mathrm{P} 3$, leading to activation of protein kinase B (PKB /Akt) pathway, enabling the differentiation and survival of human islet cells [42].

Laminin-411 and laminin-511 are two major laminin isoforms in vascular basement membranes [37]. Through activation of the FAK/ERK pathway, they can bind to $\beta 1$-integrin on $\beta$ cells, increasing the expression of Pdx-1 and insulin, contributing to the differentiation and survival of human fetal pancreatic islet cells [45]. Other studies found that laminin- 1 can bind $\alpha 6$-integrin and $\alpha$-DG on $\beta$ cells to promote cell survival and $\beta$ cell differentiation $[46,47]$. When islets are exposed to interleukin-1 $\beta$, which is an important mediator of the inflammatory response, the expression of laminin-332 is unregulated, protecting $\beta$ cells from apoptosis through phosphatidylinositol 3-kinase (PI3-K) pathway [48].

In addition to laminin and collagen, many other basement membrane may also exert beneficial effects to $\beta$ cell. Fibronectin is a glycoprotein that binds to integrins, which mediates a wide variety of cellular interactions. It plays roles in cell adhesion, migration, growth and differentiation [49]. It can maintain integrity of islet structure in vitro, and increase insulin release by decreasing expression of SUR1 [50], which is a submit of ATP-sensitive K-channels, closing the channel can result in insulin release [51]. Heparan sulfate is a linear polysaccharide that is expressed at high levels in mouse islets [42]. It can protect $\beta$ cells resistant to damage from ROS in vitro; and when heparan sulfate is degraded islets will be autoimmune destructed in NOD mice, showing essential for $\beta$ cell survival [52].

Studies found that collagen, laminin, fibronectin, and other basement membrane can bind to TSP-1, which can activate TGF- $\beta$ and affect the composition of basement membrane, such as inducing the synthesis of collagens and other matrix molecules [53]. It may shows the extracellular proteins which have synergistic effect to $\beta$ cells.

\section{Connective tissue growth factor}

Connective tissue growth factor (CTGF) is protein that is highly expressed in endothelial cells during development [54, 55], and functions as an inducer of $\beta$ cell proliferation, differentiation, and islet morphogenesis [56]. The loss of CTGF derived from endothelial cells results in embryonic $\beta$ cell proliferation and islet vascularity decreased [56]. Studies found that CTGF can induce the production of basement membrane components, such as collagen and fibronectin 
by mediating transforming growth factor $\beta$ (TGF- $\beta$ ), and it has a domain that is thrombospondin-1 (TSP1) repeat, all of which have shown beneficial effects on $\beta$ cell [54]. Furthermore, CTGF induces expression of platelet-derived growth factor subunit B (PDGF-B) in endothelial cells, required for pericytes recruitment and retention, which are embedded in basement membrane [54]. Studies found that pericytes can increase eNOS levels and vasodilatation, which have contribute to the development of insulin resistance [57].

\section{Endothelin-1}

Endothelin-1 (ET-1) is a potent endothelium-derived vasoconstrictor [58]. Insulin can stimulate the expression and secretion of ET-1 from bovine endothelial cells [59], and hyperinsulinemia stimulates the production of plasma ET-1 in humans [60]. Studies found it can stimulate insulin secretion via ETA receptors in $\beta$ cell [61], which increase calcium ion channels influx [62] and activate PKC pathway [61], acting as an important intracellular amplifier in insulin secretory process in islets [61]. On the other hand, ET-1 can upregulate the expression of Forkhead box O1 (FOXO1) gene on endothelial cells, which plays an important role in endothelial cell survival [63].

\section{The endocrine role of $\beta$ cells to islet endothelial cells}

Apart from the effect of endothelial cells on $\beta$ cells by paracrine fashion, $\beta$ cells can also secrete many proangiogenic factors which promote endothelial cells proliferation, influence the function of endothelial cells, and increase vascularization [3, 64].

Vascular endothelial growth factor-A (VEGF-A) is a major contributor to the proliferation, migration survival and permeability of endothelial cells [65]. If VEGFR is blocked by antagonists, such as AG-013736, a small-molecule VEGFR tyrosine kinase inhibitor, the density of capillaries is significantly reduced [66]. In islets, $\beta$ cells secrete large amounts of VEGF-A early in development and throughout adult life [67], and it's controlled by pancreatic and duodenal homeobox 1 $(\mathrm{Pdx} 1)$ promoter [57].

Experiments discovered that VEGF is important to the success of islets transplantation. During the first few days after transplantation, if subjected to hypoxia, it induces VEGF producing, thereby initiating revas- cularization and maintaining the vascular permeability of the rat grafted islets [68]. Upregulation of VEGF accelerates islet revascularization, which increases the survival of transplanted islets [69]. Experiments have shown that VEGF knocked-out mice contain defective remaining capillaries. Consequently, which results in the decreased release of glucose-stimulating insulin, and the impairment of glucose homeostasis [70]. On the other hand, when suffers hyperglycemia, VEGF-A expression is decreased because of islet inflammation, inducing islet vasculature density reducing $[6,71]$. Is the VEGF-A the more, the better? The answer is negative. VEGF-A overexpression can increase intraislet endothelial cells proliferation and vascularization, but the endothelial cells may not form functional vessels, which limit $\beta$ cell proliferation, and alter islet morphology [72].

VEGF-A mainly acts on VEGFR-2 (Flk-1) on endothelial cells [73]. Studies found that VEGFR-2 is highly expressed in intra-islet capillaries, while in microvasculature of exocrine tissue, and even in islet arterioles and venules, it is downregulated [74]. When VEGF-A binds to VEGFR-2, the activating mechanism of signal transductions are multiple. 1) It results in autophosphorylation of tyrosine residues, activate protein kinase $\mathrm{C}$ (PKC)-Ras pathway, which induces mitogen-activated protein kinase (MAPK) /extracellular regulated kinase (ERK) pathway activating transcription factors, causing cells proliferation [65]. 2) It activates phosphatidylinositol (PI) 3-kinase (PI3K)/protein kinase $\mathrm{B}(\mathrm{Akt} / \mathrm{PKB})$ pathway, through increasing lipid phosphatidylinositol $(3,4,5) \mathrm{P}$, activates downstream protein kinase B (PKB /Akt) pathway and endothelial nitric oxide synthase, promotes cells survival and increase of vascular permeability and cellular migration [65]. 3) It activates p38MAPK and focal adhesion kinase, inducing cytoskeletal reorganization ad cell migration [65]. Other opinions demonstrate that it can activate signal transducer and activator of transcription 3 (STAT3) signaling, developing pancreatic microvasculature [75]. Sitagliptin, a Dipeptidyl Peptidase IV Inhibition, can activate cAMP response element-binding (CREB) in $\beta$ cell, increase VEGF secretion, inducing neovascularization of islets [76].

Angiopoietin-1(Ang-1), which functions as a ligand that binds to endothelium-specific receptor tyrosine kinase Tie-2, and activates the $\mathrm{pI} 3 \mathrm{k} / \mathrm{Akt}$ pathway on endothelial cells, as well as prevents endothelial cells apoptosis [77], is a powerful vasoactive factor. 


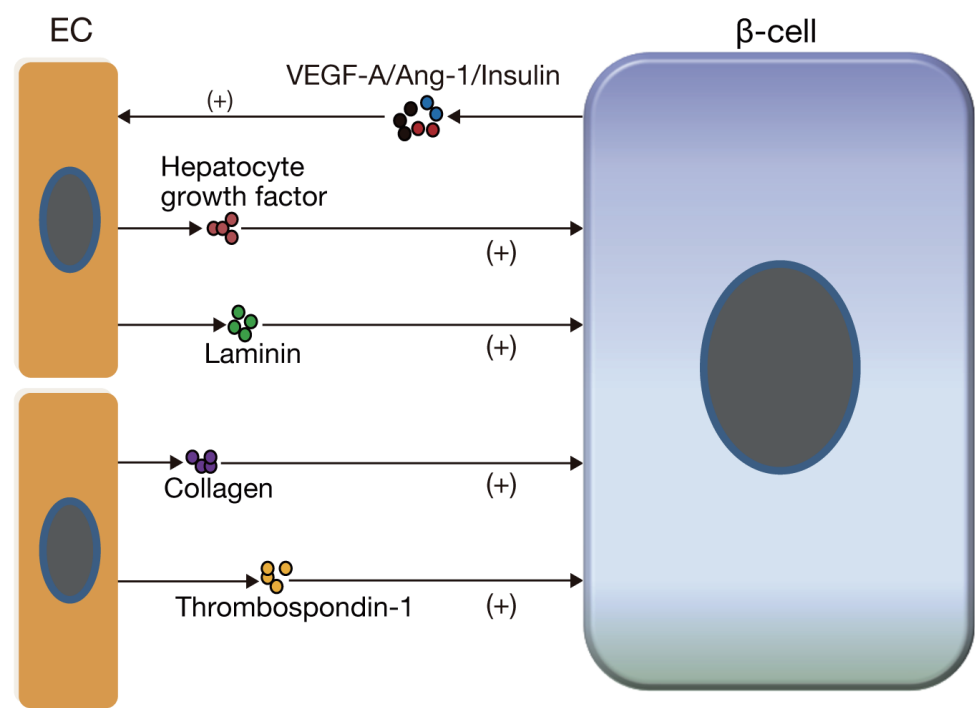

Fig. 1 The following model shows the intra-islet crosstalk between endothelial cell and $\beta$-cell mediated by different endocrine factors. Hepatocyte growth factors (HGF), thrombospondin-1(TSP-1), laminins, collagens are vasoactive substances secreted by endothelial cell, promoting $\beta$-cell continuous growth, differentiation, and production of insulin. Vascular endothelial growth factor-A (VEGF-A), angiopoietin-1 and insulin are important factors for endothelial cell proliferation, which is mainly produced by $\beta$-cell in islet.

Ang-1 can inhibit the expression of inflammationassociated adhesion molecules, including E-selectin and Intercellular Adhesion Molecule 1 (ICAM-1). protecting against damage induced by inflammatory factor, and regulates the integrity of blood vessels [78]. In islets, Ang-1 is expressed only by the $\beta$ cells [74]. Unlike the overexpression of VEGF-A impact the function of $\beta$ cells, increased expression of Ang-1 just alter islet endothelial cells ultrastructure, not do islet differentiation, development, or morphology [72].

As $\beta$ cells and intra-islet endothelial cells have close relationship, insulin may influence the function of endothelial cells. Insulin receptor can be detected on endothelial cells [79]. It is can activate PI-3 kinase which regulate the expression of eNOS gene in endothelial cells, promoting intra-islet blood flow and modulates vascular tone $[67,80]$. When suffering diabetes, the inhibition of PI-3 kinase activity may lead to endothelial dysfunctions [80]. Study found insulin can be synergistic with VEGF-A in vivo and in vitro, which can induce endothelial cells secreting HGF and enhance $\beta$ cells proliferation [25].

\section{Conclusion}

Increasing number of studies contribute to the consensus that endothelial cells have positive effects in the islet microenvironment. Endothelial cells can act as endocrine cells. Hepatocyte growth factors (HGF), thrombospondin-1(TSP-1), laminins, collagens and other active substances from endothelial cells induce $\beta$ cells proliferation, insulin secretion next to the vessels. The islets utilize VEGF-A, angiopoietin-1 and insulin signals to increase the interaction with endothelial cells (Fig. 1). As the endocrine role of endothelial cells to $\beta$ cells, it may be a novel target to stimulate $\beta$ cells regeneration, promote vascularization post islet transplantation strategy in the treatment of diabetes mellitus.

\section{References}

1. Wang X, Meloche MF, Verchere CB, Ou D, et al. (2011) Improving islet engraftment by gene therapy. $J$ Transplant 2011: 594851.

2. Leoni L, Roman BB (2010) MR imaging of pancreatic islets: tracking isolation, transplantation and function. Curr Pharm Des 16: 1582-1594.

3. Konstantinova IF, Lammert E (2004) Microvascular development: learning from pancreatic islets. Bioessays 
26: 1069-1075.

4. Olsson R, Carlsson P (2006) The pancreatic islet endothelial cell: emerging roles in islet function and disease. Int J Biochem Cell Biol 38: 710-714.

5. Belle TL, Coppieters K, Coppieters KT, von Herrath M, Herrath M (2011) Type 1 diabetes: etiology, immunology, and therapeutic strategies. Physiol Rev 91(1): 79-118.

6. Grapensparr L, Lerud J, Vasylovska S, Carlsson P (2011) The therapeutic role of endothelial progenitor cells in Type 1 diabetes mellitus. Regen Med 6: 599605.

7. Yang X, Michie SA, Mebius RE, Tisch RF, Weissman IF, et al. (1996) The role of cell adhesion molecules in the development of IDDM: implications for pathogenesis and therapy. Diabetes 45: 705-710.

8. Pan X, Xue W, Li Y, Feng X, Tian X, et al. (2011) Islet graft survival and function: concomitant culture and transplantation with vascular endothelial cells in diabetic rats. Transplantation 92: 1208-1214.

9. Nyqvist D, Speier S, Rodriguez-Diaz R, Molano RD, Lipovsek S, et al. (2011) Donor islet endothelial cells in pancreatic islet revascularization. Diabetes 60: 25712577.

10. Rivas-Carrillo SD, Kanamune J, Iwanaga Y, Uemoto S, Daneri-Navarro A, et al. (2011) Endothelial cells promote pancreatic stem cell activation during islet regeneration in mice. Transplant Proc 43: 3209-3211.

11. Talavera-Adame DF, Wu G, He Y, Ng TT, Gupta A, et al. (2011) Endothelial cells in co-culture enhance embryonic stem cell differentiation to pancreatic progenitors and insulin-producing cells through BMP signaling. Stem Cell Rev 7: 532-543.

12. Eberhard D, Kragl M, Lammert E (2010) 'Giving and taking': endothelial and beta-cells in the islets of Langerhans. Trends Endocrinol Metab 21: 457-463.

13. Takebayashi TF, Iwamoto MF, Jikko AF, Matsumura TF, Enomoto-Iwamoto MF, et al. (1995) Hepatocyte growth factor/scatter factor modulates cell motility, proliferation, and proteoglycan synthesis of chondrocytes. J Cell Biol 129: 1411-1419.

14. Cassano MF, Biressi S, Finan A, Benedetti LF, Omes $\mathrm{CF}$, et al. (2008) Magic-factor 1, a partial agonist of Met, induces muscle hypertrophy by protecting myogenic progenitors from apoptosis. PLoS One 3: e3223.

15. Cooper C (1992) The met oncogene: from detection by transfection to transmembrane receptor for hepatocyte growth factor. Oncogene 7: 3-7.

16. Gentile A, Trusolino L, Comoglio P (2008) The Met tyrosine kinase receptor in development and cancer. Cancer Metastasis Rev 27: 85-94.

17. O'Brien LE, Tang K, Kats ES, Schutz-Geschwender A, Lipschutz JH, et al. (2004) ERK and MMPs sequentially regulate distinct stages of epithelial tubule development. Dev Cell 7: 21-32.
18. Garcia-Ocana A, Vasavada RC, Cebrian A, Reddy V, Takane KK, et al. (2001) Transgenic overexpression of hepatocyte growth factor in the beta-cell markedly improves islet function and islet transplant outcomes in mice. Diabetes 50: 2752-2762.

19. Calvo E, Boucher C, Pelletier G, Morisset J (1996) Ontogeny of hepatocyte growth factor and c-met/hgf receptor in rat pancreas. Biochem Biophys Res Commun 229: 257-263.

20. Otonkoski T, Cirulli V, Beattie M, Mally MI, Soto G, et al. (1996) A role for hepatocyte growth factor/scatter factor in fetal mesenchyme-induced pancreatic beta-cell growth. Endocrinology 137: 3131-3139.

21. Fiaschi-Taesch N, Stewart AF, Garcia-Ocana A, GarciaOcana A (2007) Improving islet transplantation by gene delivery of hepatocyte growth factor (HGF) and its downstream target, protein kinase B (PKB)/Akt. Cell Biochem Biophys 48: 191-199.

22. Vasavada RC, Wang L, Wang L, Fujinaka Y, Takane KK, et al. (2007) Protein kinase C-zeta activation markedly enhances beta-cell proliferation: an essential role in growth factor mediated beta-cell mitogenesis. Diabetes 56: 2732-2743.

23. Garcia-Ocana A, Takane KK, Syed MA, Philbrick WM, Vasavada RC, et al. (2000) Hepatocyte growth factor overexpression in the islet of transgenic mice increases beta cell proliferation, enhances islet mass, and induces mild hypoglycemia. J Biol Chem 275: 1226-1232.

24. Nakano M, Yasunami Y, Maki T, Kodama S, Ikehara $\mathrm{Y}$, et al. (2000) Hepatocyte growth factor is essential for amelioration of hyperglycemia in streptozotocininduced diabetic mice receiving a marginal mass of intrahepatic islet grafts. Transplantation 69: 214-221.

25. Johansson M, Mattsson G, Andersson A, Jansson L, Carlsson P (2006) Islet endothelial cells and pancreatic beta-cell proliferation: studies in vitro and during pregnancy in adult rats. Endocrinology 147: 2315-2324.

26. Rao P, Cozar-Castellano I, Roccisana J, Vasavada R, Garcia-Ocana A (2004) Hepatocyte growth factor gene therapy for islet transplantation. Expert Opin Biol Ther 4: 507-518.

27. Chen HF, Herndon ME, Lawler J (2000) The cell biology of thrombospondin-1. Matrix Biol 19: 597-614.

28. Crawford SE, Stellmach VF, Murphy-Ullrich JE, Ribeiro SM, Lawler JF, et al. (1998) Thrombospondin-1 is a major activator of TGF-beta1 in vivo. Cell 93: 11591170.

29. Olerud J, Mokhtari D, Johansson M, Christoffersson G, Lawler J, et al. (2011) Thrombospondin-1: an islet endothelial cell signal of importance for beta-cell function. Diabetes 60: 1946-1954.

30. Atfi A, Djelloul S, Chastre E, Davis R, Gespach C (1997) Evidence for a role of Rho-like GTPases and stress-activated protein kinase/c-Jun N-terminal kinase (SAPK/JNK) in transforming growth factor beta-medi- 
ated signaling. $J$ Biol Chem 272: 1429-1432.

31. Smart NG,Apelqvist A, Apelqvist AA, Gu X, Harmon EB, et al. (2006) Conditional expression of Smad7 in pancreatic beta cells disrupts TGF-beta signaling and induces reversible diabetes mellitus. PLoS Biol 4: e39.

32. Tada H, Kuboki K, Nomura K, Inokuchi T (2001) High glucose levels enhance TGF-beta1-thrombospondin-1 pathway in cultured human mesangial cells via mechanisms dependent on glucose-induced PKC activation. $J$ Diabetes Complications 15: 193-197.

33. Olerud J, Johansson M, Lawler J, Welsh N, Carlsson P (2008) Improved vascular engraftment and graft function after inhibition of the angiostatic factor thrombospondin-1 in mouse pancreatic islets. Diabetes 57: 18701877.

34. Adams J, Lawler J (2011) The thrombospondins. Cold Spring Harb Perspect Biol 3: a009712.

35. Dawson DW, Pearce SF, Zhong RF, Silverstein RL, Frazier WA, et al. (1997) CD36 mediates the In vitro inhibitory effects of thrombospondin-1 on endothelial cells. J Cell Biol 138: 707-717.

36. Grant DS, Kleinman HK, Martin G (1990) The role of basement membranes in vascular development. Ann $N$ Y Acad Sci 588: 61-72.

37. Nikolova G, Jabs N, Konstantinova I, Domogatskaya A, Tryggvason K, et al. (2006) The vascular basement membrane: a niche for insulin gene expression and Beta cell proliferation. Dev Cell 10: 397-405.

38. Virtanen IF, Banerjee MF, Palgi JF, Korsgren OF, Lukinius AF, et al. (2008) Blood vessels of human islets of Langerhans are surrounded by a double basement membrane. Diabetologia 51: 1181-1191.

39. Otonkoski T, Banerjee M, Korsgren O, Thornell LE, Virtanen I (2008) Unique basement membrane structure of human pancreatic islets: implications for betacell growth and differentiation. Diabetes Obes Metab 10 Suppl 4: 119-127.

40. Wang R, Rosenberg L (1999) Maintenance of beta-cell function and survival following islet isolation requires re-establishment of the islet-matrix relationship. $J$ Endocrinol 163: 181-190.

41. LeBleu VS, Macdonald B, Macdonald B, Kalluri R (2007) Structure and function of basement membranes. Exp Biol Med (Maywood) 232: 1121-1129.

42. Krishnamurthy MF, et al. (2011) Integrin \{alpha\}3, but not $\{$ beta 1 , regulates islet cell survival and function via PI3K/Akt signaling pathways. Endocrinology 152: 424435.

43. Kaido T, Yebra M, Cirulli V, Montgomery A (2004) Regulation of human beta-cell adhesion, motility, and insulin secretion by collagen IV and its receptor alpha1beta1. J Biol Chem 279: 53762-53769.

44. Riopel MF, Krishnamurthy MF, Li JF, Liu S, Leask AF, et al. (2011) Conditional beta1-integrin-deficient mice display impaired pancreatic beta cell function. J Pathol
224: 45-55.

45. Saleem S, Li J, Yee SP, Fellows GF, Goodyer C, et al. (2009) beta1 integrin/FAK/ERK signalling pathway is essential for human fetal islet cell differentiation and survival. J Pathol 219: 182-192.

46. Jiang F, Georges-Labouesse E, Harrison LC (2001) Regulation of laminin 1-induced pancreatic betacell differentiation by alpha6 integrin and alphadystroglycan. Mol Med 7(2): 107-114.

47. Jiang FX, Cram DS, DeAizpurua HJ, Harrison LC (1999) Laminin-1 promotes differentiation of fetal mouse pancreatic beta-cells. Diabetes 48: 722-730.

48. Armanet M, Wojtusciszyn A, Morel P, Parnaud G, Rousselle P, et al. (2009) Regulated laminin-332 expression in human islets of Langerhans. FASEB J 23: 4046-4055.

49. Pankov R, Yamada K (2002) Fibronectin at a glance. $J$ Cell Sci 115: 3861-3863.

50. Daoud J, Petropavlovskaia M, Rosenberg L, Tabrizian M (2010) The effect of extracellular matrix components on the preservation of human islet function in vitro. Biomaterials 31: 1676-1682.

51. Ashcroft F (1996) Mechanisms of the glycaemic effects of sulfonylureas. Horm Metab Res 28: 456-463.

52. Ziolkowski AF, Popp SK, Freeman C, Parish CR, Simeonovic CJ (2012) Heparan sulfate and heparanase play key roles in mouse beta cell survival and autoimmune diabetes. J Clin Invest 122: 132-141.

53. Tan K, Lawler J (2009) The interaction of Thrombospondins with extracellular matrix proteins. $J$ Cell Commun Signal 3: 177-187.

54. Hall-Glenn FF, De Young RA, Huang BL, Handel BF, Hofmann JJ, et al. (2012) CCN2/connective tissue growth factor is essential for pericyte adhesion and endothelial basement membrane formation during angiogenesis. PLoS One 7: e30562.

55. Crawford LA, Guney M, Guney MA, Oh YA, Deyoung RA, et al. (2009) Connective tissue growth factor (CTGF) inactivation leads to defects in islet cell lineage allocation and beta-cell proliferation during embryogenesis. Mol Endocrinol 23: 324-336.

56. Guney MA, Petersen C, Petersen CP, Boustani A, Boustani AF, et al. (2011) Connective tissue growth factor acts within both endothelial cells and beta cells to promote proliferation of developing beta cells. Proc Natl Acad Sci U S A 108: 15242-15247.

57. Richards OC, Raines SM, Attie AD (2010) The role of blood vessels, endothelial cells, and vascular pericytes in insulin secretion and peripheral insulin action. Endocr Rev 31: 343-363.

58. Yanagisawa MF, Kurihara HF, Kimura S, Tomobe YF, Kobayashi MF, et al. (1988) A novel potent vasoconstrictor peptide produced by vascular endothelial cells. Nature 332: 411-415.

59. Hu RM, Levin ER, Pedram A, Frank H (1993) Insulin 
stimulates production and secretion of endothelin from bovine endothelial cells. Diabetes 42: 351-358.

60. Ferri C, Bellini C, Desideri G, De-Mattia G, Santucci A (1996) Endogenous insulin modulates circulating endothelin-1 concentrations in humans. Diabetes Care 19: 504-506.

61. Gregersen S, Thomsen JL, Hermansen K (2000) Endothelin-1 (ET-1)-potentiated insulin secretion: involvement of protein kinase $\mathrm{C}$ and the ET(A) receptor subtype. Metabolism 49: 264-269.

62. Gregersen S, Thomsen JL, Brock B, Hermansen K (1996) Endothelin-1 stimulates insulin secretion by direct action on the islets of Langerhans in mice. Diabetologia 39: 1030-1035.

63. Cifarelli VF, Lee S, Kim DH, Zhang TF, Kamagate AF, et al. (2012) FOXO1 mediates the autocrine effect of endothelin-1 on endothelial cell survival. Mol Endocrinol 26: 1213-1224.

64. Ranjan AK, Joglekar MV, Hardikar A (2009) Endothelial cells in pancreatic islet development and function. Islets 1: $2-9$.

65. Hoeben AF, Landuyt BF, Highley MS, Wildiers HF, Oosterom AT, et al. (2004) Vascular endothelial growth factor and angiogenesis. Pharmacol Rev 56: 549-580.

66. Kamba T, Tam BY, Hashizume H, Haskell A, Sennino B, et al. (2006) VEGF-dependent plasticity of fenestrated capillaries in the normal adult microvasculature. Am J Physiol Heart Circ Physiol 290: H560-H576.

67. Peiris H, Bonder CS, Coates PT, Keating DJ, Jessup CF (2014) The $\beta$-cell/EC axis: how do islet cells talk to each other? Diabetes 63: 3-11.

68. Vasir B, Aiello LP, Yoon KH, Quickel RR, Bonner-Weir S, et al. (1998) Hypoxia induces vascular endothelial growth factor gene and protein expression in cultured rat islet cells. Diabetes 47: 1894-1903.

69. Cheng Y, Liu Y, Zhang J, Li T, Zhao N (2007) Elevation of vascular endothelial growth factor production and its effect on revascularization and function of graft islets in diabetic rats. World J Gastroenterol 13: 2862-2866.

70. Shalaby F, Rossant J, Yamaguchi TP, Gertsenstein M, Wu XF, et al. (1995) Failure of blood-island formation and vasculogenesis in Flk-1-deficient mice. Nature 376: 62-66.

71. Akirav EM, Baquero MT, Opare-Addo LW, Akirav
MF, Galvan E, et al. (2011) Glucose and inflammation control islet vascular density and beta-cell function in NOD mice: control of islet vasculature and vascular endothelial growth factor by glucose. Diabetes 60: 876883.

72. Cai Q, Brissova M, Reinert RB, Pan FC, Brahmachary $P$, et al. (2012) Enhanced expression of VEGF-A in $\beta$ cells increases endothelial cell number but impairs islet morphogenesis and $\beta$ cell proliferation. Dev Biol 367: 40-54.

73. Eichmann A, Simons M (2012) VEGF signaling inside vascular endothelial cells and beyond. Curr Opin Cell Biol 24: 188-193.

74. Brissova M, Shostak A, Shiota M, Wiebe PO, Poffenberger G, et al. (2006) Pancreatic islet production of vascular endothelial growth factor--a is essential for islet vascularization, revascularization, and function. Diabetes 55: 2974-2985.

75. Kostromina E, Wang X, Han W (2013) Altered islet morphology but normal islet secretory function in vitro in a mouse model with microvascular alterations in the pancreas. PLoS One 8: e71277.

76. Samikannu B, Chen C, Lingwal N, Padmasekar M, Engel FB, et al. (2013) Dipeptidyl Peptidase IV Inhibition Activates CREB and Improves Islet Vascularization through VEGF-A/VEGFR-2 Signaling Pathway. PLoS One 8: e82639.

77. Su DF, Zhang NF, He JF, Qu S, Slusher S, et al. (2007) Angiopoietin-1 production in islets improves islet engraftment and protects islets from cytokine-induced apoptosis. Diabetes 56: 2274-2283.

78. Brindle NP, Alitalo K (2006) Signaling and functions of angiopoietin-1 in vascular protection. Circ Res 98: 1014-1023.

79. Kondo T, Vicent D, Suzuma K, Yanagisawa M, King GL, et al. (2003) Knockout of insulin and IGF-1 receptors on vascular endothelial cells protects against retinal neovascularization. J Clin Invest 111: 1835-1842.

80. Kuboki K, Jiang ZY, Takahara N, Ha SW, Igarashi M, et al. (2000) Regulation of endothelial constitutive nitric oxide synthase gene expression in endothelial cells and in vivo : a specific vascular action of insulin. Circulation 101: 676-681. 